\title{
Auditoría de gestión y su incidencia en la eficiencia y eficacia de las operaciones de una empresa comercial.
}

\section{Management audit and its impact on the efficiency and effectiveness of the operations of a commercial company.}

\section{Juan Carlos Castillo Morocho. ${ }^{1}$, Juan Carlos Erazo Álvarez. ${ }^{2}$, Cecilia Ivonne Narváez Zurita.$^{3} \&$ Mireya Magdalena Torres Palacios. ${ }^{4}$ \\ DOI: https://doi.org/10.33262/visionariodigital.v3i2.1.551}

\begin{abstract}
.
Nowadays, a management audit is a valuable tool in the business environment. Therefore, its support help to maintain correct control over administrative and financial operations, among others. Based on International Accounting Standards, Internal Control Standards for the Public and Private Control, and document review of significant authors in this area, such as Franklin (2007), White (2006) Rose (2013) and Velasquez (2013) this article analyzes the implementation the management audit in the company "Multimotos S.A.", in the city of Cuenca - Ecuador, in the period 2018.

Methodologically the study applied a management audit to check control procedures regard to the principles of the COSO report. The management audit was verified through variables using surveys to the board of managers. The results show the degree of efficiency achieved by the company in the use of their resources, the effectiveness in achieving the scheduled goals, and the quality of their goods and services reflected in the high degree of satisfaction of its customers. Its essential role is highlighted as a systematic and thorough assessment of the administrative, operative, and financial information. It evaluates the effectiveness in achieving the goals based on standards previously established in the company and the efficiency of the results according to economic, human, and material resources.
\end{abstract}

Keywords: Management, effectiveness, quality, internal control

\footnotetext{
${ }^{1}$ Universidad Católica de Cuenca, Posgradista Maestría en Contabilidad y Auditoría, Cuenca, Ecuador, jccastillom925@psg.ucacue.edu.ec

${ }^{2}$ Universidad Católica de Cuenca, Subdirección de Posgrado, Cuenca, Ecuador, jcerazo@ucacue.edu.ec

${ }^{3}$ Universidad Católica de Cuenca, Subdirección de Posgrado, Cuenca, Ecuador, inarvaez@ucacue.edu.ec

${ }^{4}$ Universidad Católica de Cuenca, Subdirección de Posgrado, Cuenca, Ecuador, mireya.torres@ ucacue.edu.ec

Empresa \& Gestiòn

Página 159
} 


\section{Resumen.}

Hoy en día la evaluación de la gestión es un aspecto muy importante en el entorno empresarial, su trascendencia se refleja en contar con una adecuada herramienta, que aporte a mantener un control adecuado sobre las operaciones administrativas, financieras y de otra índole. Basado en las Normas Internacionales de Auditoría, Normas de Control Interno para el sector público y privado y la revisión documental de autores reconocidos en el área como, Franklin (2007), Blanco (2006) Subía (2013) y Velásquez (2013) el artículo analiza el proceso de ejecución de la auditoría de gestión en la empresa "Multimotos S.A.", de la ciudad de Cuenca - Ecuador, en el período 2018. Metodológicamente se aplicó una auditoría de gestión, para revisar aquellos procedimientos de control en relación con los componentes del informe COSO, aplicando las preguntas del cuestionario a los Gerentes: General, Comercial y Financiero y Jefe de Talento Humano y verificar la gestión a través de indicadores. Sus resultados demuestran el grado de eficiencia alcanzado por la empresa en el uso de sus recursos, la eficacia en cuanto al logro de las metas programadas y la calidad de sus bienes y servicios reflejada en el grado de satisfacción de sus clientes. Se destaca su importancia como un instrumento de evaluación sistemática y completa de la información administrativa, operativa y financiera, evalúa la eficacia en el logro de las metas y en función de los estándares previamente establecidos en la empresa, la eficiencia de sus resultados de acuerdo a los recursos financieros, humanos y materiales empleados.

Palabras claves: gestión, eficiencia, eficacia, calidad, control interno.

\section{Introducción.}

La empresa "Multimotos S.A.", es una compañía de nacionalidad ecuatoriana, creada bajo la figura de sociedad anónima. Tiene su domicilio en la ciudad de Cuenca y cuenta en la actualidad con 38 sucursales dentro de todo el país. La entidad tiene como objeto social la compra - venta al por mayor y menor de motos, artículos e implementos deportivos, accesorios, repuestos e insumos, administración de talleres de reparación de motos, representación de marcas y servicios y presentación de servicios relacionados con el objetivo principal. La empresa ha alcanzado un posicionamiento aceptable en el mercado y ofrece productos de calidad, dispone de talento humano capacitado, recursos materiales y financieros necesarios para su operación, los cuales deben ser administrados adecuadamente para lograr su optimización y contribución en el logro de sus metas empresariales.

En este sentido, es importante medir el comportamiento de la organización en función de las metas planteadas y encaminar las acciones, actividades o procesos a la optimización de los recursos. Es primordial conocer el nivel de satisfacción y expectativas de los clientes a fin de 
elevar los niveles de comportamiento de la empresa, para la producción de bienes y servicios de calidad y altamente competitivos.

Hoy en día la evaluación de la gestión es un aspecto muy importante en el entorno empresarial, su trascendencia se refleja en contar con una adecuada herramienta, que aporte a mantener un control idóneo sobre las operaciones administrativas, financieras y de otra índole.

Dicho control debe ser desarrollado por medio de la auditoria de gestión, siendo su objetivo fundamental el medir el grado de eficiencia y eficacia con que se utilizan los recursos disponibles y se alcanzan los objetivos planteados por la entidad. Se constituye en la herramienta ideal para racionalizar las operaciones y situar la administración hacia la obtención de rendimientos. Al respecto, Velásquez (2013) manifiesta que en la actualidad el concepto de Auditoría de Gestión se ha fortalecido mediante actividades ordenadas y sistemáticas que se enfocan en evaluar la gestión de las empresas, para obtener una opinión profesional, independiente y objetiva de cómo se están gestionando los recursos, cómo se están desarrollando los procesos, cuál es el grado de responsabilidad de la dirección, si los productos o servicios se han realizado cumpliendo criterios de calidad.

Por otro lado, los cambios de los medios tecnológicos, el talento humano, el servicio al cliente-usuario y la mejora continua de procesos se convierten en factor clave para la subsistencia de las organizaciones. Por lo que es menester que la alta gerencia realice una excelente administración mediante la coherencia y cohesión de las funciones de planificación, organización, dirección y centrar el análisis en el control y su vinculación con los riesgos del negocio. De acuerdo a Dextre y Del Pozo (2012) es aquí donde aparece el control como la función de la administración que busca asegurar que las actividades se desenvuelvan tal y como han sido establecidas para cumplir los propósitos de la entidad en el logro de las metas y objetivos planeados. Puesto que el control asume la función de aseguramiento de actividades, ambos se encuentran íntimamente ligados en su operatividad. En efecto, las actividades, al estar vinculadas a riesgos de no cumplimiento o la posibilidad de errores o desviaciones en su ejecución, tienen en el control la mitigación de esos riesgos me-diente acciones de prevención, detección o corrección.

La gestión empresarial, abarca una serie de principios, encaminados a diligenciar de forma efectiva el negocio, con el objetivo de asegurar su supervivencia y crecimiento, comprende actividades diferentes que implica el establecimiento de metas y objetivos, así como la evaluación de su desempeño. Esta necesidad de determinar el grado de eficiencia, eficacia, y calidad en la utilización de los recursos disponibles, el desarrollo de procesos y la entrega de productos, acordes con las necesidades de los clientes debe ser satisfecha bajo el enfoque de la auditoría de gestión. En este contexto, desarrollar una auditoría de gestión en la empresa "Multimotos S.A." con el propósito obtener evidencia suficiente del grado de eficiencia, 
eficacia y calidad en el logro de metas y objetivos propuestos, constituye la esencia de este estudio, su realización implica definir una estrategia de trabajo a la medida de la organización auditada, para considerar las áreas que requieren acciones correctivas y generar acciones oportunas que mejoren la gestión.

\section{Marco conceptual de la Auditoría de Gestión.}

Con el afán de alcanzar una mayor comprensión a cerca de los fundamentos teóricos de la auditoría de gestión, resulta importante hacer hincapié en las conceptualizaciones que la implican.

Velásquez (2013) define a la auditoría de gestión como una actividad que, sobre la base de un modelo y un marco normativo, permite determinar el grado de eficiencia, eficacia, y calidad en la utilización de los recursos disponibles, el desarrollo de procesos y la entrega de productos o de servicios, acordes con las necesidades de los clientes, los mismos que podrán ser mejorados en forma continua, a través de la aplicación de las recomendaciones emanadas del informe de auditoría. Por su parte, Cantos (2019) afirma que la auditoria de gestion es un examen completo y provechoso cuya finalidad es: la revisión y el control de los recursos humanos y materiales empleados en la consecución de las metas trazadas por la organización y en concordancia con las políticas, leyes y reglamentos que rigen su accionar. Surge "de la necesidad de medir y cuantificar los logros alcanzados en un período de tiempo determinado. Emerge como una manera efectiva de poner en orden los recursos de la entidad para lograr un mejor desempeño y productividad"

Franklin (2007a) refuerza lo expresado por Cantos y define a la auditoría de gestión como "la revisión analítica total o parcial de una organización con el propósito de precisar su nivel de desempeño y perfilar oportunidades de mejora para innovar valor y lograr una ventaja competitiva sustentable" (p.11). En tanto que, La Contraloría General del Estado (2003) en el manual de auditoría de gestión la conceptualiza como un análisis ordenado profesional que lo realiza una o varias personas multidisciplinarias con el fin de evaluar la eficiencia de cómo se encuentra la empresa en concordancia con los objetivos y metas planteadas por la alta gerencia de la empresa, para que de esta forma se mida el nivel de economía y eficacia en el uso de todos sus recursos económicos, evaluando la eficacia de sus servicios, obras o bienes, al momento de realizar la producción de esta manera visualizar el efecto socio económico que se originan de sus actividades.

Para finalizar este marco conceptual se concluye describiendo a la auditoría de gestión como la evaluación sistemática y completa de la información administrativa, operativa y financiera realizada por un equipo multidisciplinario, quienes, a través de la aplicación de diversos procedimientos y técnicas, evalúa la eficacia en el logro de las metas y en función de los estándares previamente establecidos en la empresa, la eficiencia de sus resultados de acuerdo a los recursos financieros, humanos y materiales empleados. 
La auditoría debe entenderse siempre como una herramienta de análisis y control de la gestión realizada, cuyos resultados siempre serán positivos para el auditado, ya que aportan una visión muy certera del estado de cumplimiento legal, del estado de implantación del sistema, de sus puntos fuertes y de las áreas de mejora. En definitiva, la auditoria muestra el camino recorrido y su nivel de eficacia, y marca las pautas que se deben seguir (De Salas Nestares, Arriaga Álvarez, y Pla Velarde, 2006).

La auditoría de gestión es una actividad que permite calcular y medir los logros alcanzados por la empresa en un lapso de tiempo determinado, representa la forma efectiva de colocar en orden los recursos de la entidad para alcanzar un mejor desempeño y productividad de los mismos. Es pertinente tener en cuenta que, de acuerdo a su amplitud, también evalúa el cumplimiento de la normativa, políticas y procedimientos decretados por los órganos de control a la que se encuentran regida la empresa. Su importancia se resume en la necesidad de examinar el cumplimiento de los fines y objetivos trazados por la empresa.

El objetivo de una auditoría de gestión es descubrir las deficiencias y buscar soluciones que permitan una administración eficaz. Su objetivo principal es: Evaluar el grado de cumplimiento de la misión, políticas, objetivos, estrategias, metas, consideradas en los planes y programas a través de la aplicación de indicadores de gestión que permitan medir el grado de eficiencia, eficacia, y calidad, como también el impacto que esta genera en el sector (Velásquez, 2013).

Lo citado anteriormente, permiten obtener una visión clara sobre la finalidad de la auditoría de gestión, cuyo enfoque implica una evaluación ordenada de las operaciones de una entidad, en concordancia a su misión, proyectos o metas y respecto al empleo eficiente de los recursos, es decir su finalidad es examinar el desempeño de la organización en todas sus áreas para identificar oportunidades de mejora y contribuir a que la dirección consiga una administración más eficaz y eficiente. Entre los motivos que dan lugar a una auditoría de gestión está la necesidad de controlar la gestión de la empresa en sus diferentes niveles; eficacia, eficiencia y calidad, estos términos son definidos por León (2014) de la siguiente manera:

Eficacia: (logro de las metas y objetivos). Es el grado en que una actividad o programa alcanza los objetivos y metas propuestas. Este aspecto tiene que ver con los resultados del proceso de trabajo, respecto a la producción o servicio cumplido en la cantidad esperada.

Eficiencia: se considera como el uso inteligente de los recursos. Es alcanzar los objetivos al menor costo posible con relación a los coeficientes o estándares de producción de bienes y servicios (calidad del gasto). Se refiere a la relación entre los recursos consumidos (insumos) y la producción de bienes y servicios.

Calidad: Satisfacción percibida por el usuario o cliente. 


\section{Campo de acción de la auditoría de gestión.}

La Auditoría de Gestión puede abarcar a toda la entidad o a parte de ella, en este último caso por ejemplo un proyecto, un proceso, una actividad, un grupo de operaciones, etc. Pero el alcance también comprende la cobertura a operaciones recientemente ejecutadas o en ejecución, denominada operaciones corrientes. (Contraloría General del Estado, 2001). Según Blanco (2006) con respecto al campo de acción de la auditoría de gestión manifiesta que el desarrollo concreto de un programa de trabajo depende de las circunstancias particulares de cada entidad. Sin embargo, se señalan a continuación los enfoques que se le pueden dar al trabajo, dentro de un plan general, en las áreas principales que conforman una entidad:

- Auditoría de la gestión global del ente

- Auditoría de gestión del sistema comercial

- Auditoria de gestión del sistema financiero

- Auditoria de gestión del sistema de producción

- Auditoría de gestión de los recursos humanos

- Auditoría de gestión de sistemas administrativos. (p. 406)

Es decir, la evaluación de la gestión "puede alcanzar un sector de la economía, todas las operaciones de la entidad inclusive las financieras o puede limitarse a cualquier operación, programa, sistema o actividad específica" (Maldonado, 2006, p.26).

\section{Normas de la auditoría de gestión.}

Las normas de auditoria de gestión se fundamentan en principios que rigen el control de la gestión, las mismas que están direccionadas a evaluar el sistema de control interno como apoyo a garantizar la eficiencia y eficacia de las operaciones. Para lograr que la aplicación de estos principios sea uniforme, en el Ecuador las Normas Internacionales de Auditoria (NIAS) direccionan la ejecución de la auditoria de estados financieros y auditorias administrativas. Las pautas que se determinan son 200 Responsabilidades; 300 Planeación; 400 Control Interno; 500 Evidencia de Auditoria; 600 Uso del Trabajo de otros; y 700 Conclusiones y dictamen de la auditoria, estas normas delinean el trabajo del auditor. (Normas Internacionales de Auditoría, 2002). Para lograr una gestión eficiente y eficaz es importante diseñar un sistema de control de gestión en apoyo de la gerencia.

El control de gestión es una herramienta administrativa para valorar el grado de cumplimiento de los objetivos dispuestos por la gerencia, permite guiar a la gestión empresarial a las metas programadas con una eficiencia relevante y a su vez es un instrumento que permite evaluarla. Pérez y Veiga (2013) consideran sobre todo al control de gestión como "un mecanismo 
insustituible para la mejora continua de la calidad de la gestión. Mediante las acciones correctoras que han de derivarse de los procesos de análisis de desviaciones, se pretende superar las situaciones adversas y potenciar aún más las favorables” (p.16). Mientras que, Romero (2013) conceptualiza al control de gestión como: "el examen de eficiencia y eficacia de las entidades en la administración de los recursos, determinada mediante la evaluación de sus procesos administrativos y la utilización de indicadores de rentabilidad y desempeño" (p.260). El sistema de control de gestión permite evaluar a la empresa, proporciona a cada uno de sus usuarios, información efectiva sobre el comportamiento de los factores claves de éxito a través de los indicadores de gestión que hayan sido previamente definidos.

Los factores claves de éxito (FCE) representan un número limitado de áreas en las que los resultados de ser satisfactorios, garantizarán un rendimiento competitivo exitoso para la organización. Estas son áreas principales donde las acciones deben ir bien para que el negocio funcione: si los resultados en dichas áreas no son los adecuados, los esfuerzos de la organización, no permitirán alcanzar los objetivos definidos (Ferreras, 2010). Los FCE son aquellas características en las que la gerencia puede influir mediante determinaciones que afectan, significativamente, su posición competitiva frente a empresas de su mismo sector.

La medición de la gestión es un aspecto imprescindible en la empresa para alcanzar un conocimiento de los procesos y su relación con la gerencia de los mismos. Según Lord (como se citó en Rincón, 1998) "lo que no se puede definir no se puede medir, lo que no se puede medir no se puede mejorar, lo que se no puede mejorar se puede deteriorar" (p.46). Medir es comparar un determinado resultado con un patrón, estándar o unidad de referencia a través de indicadores de gestión.

\section{Indicadores de gestión.}

Son herramientas de gestión que proporcionan un valor de referencia a partir del cual se puede realizar un cotejo entre las metas planificadas y el cumplimiento alcanzado. Un indicador de gestión según Subía (2013) es la medición de un objetivo, meta o proceso. Deben identificar claramente la variable a medir. Los indicadores para medir eficiencia, eficacia y calidad son claramente diferenciables. No necesariamente debe presentarse en porcentaje, un indicador es aplicable si se muestra en cantidades o valores absolutos, sin embargo, en su análisis es necesario mantener consistencia con la unidad de medida y el estándar. Los indicadores proporcionan datos cuantitativos sobre el grado en que se están consiguiendo las metas de un programa, proyecto y/o la gestión de una organización, a qué costo y con qué nivel de calidad.

El uso de indicadores en la auditoría administrativa obedece a la necesidad de contar con un instrumento que permita establecer el marco de referencia para evaluar los resultados de la gestión de una organización... En este sentido, aporta elementos sustanciales para promover la mejora continua de los procesos, bienes y servicios, el empleo puntual de sus recursos y Empresa \& Gestiòn

Página 165 
abre la posibilidad de instrumentar los cambios necesarios para lograr el cumplimiento de su objeto (Franklin, 2007). Es importante que la empresa cuente con un mínimo de indicadores, que garanticen disponer de información constante, real y precisa sobre aspectos tales como la efectividad, la eficacia, la eficiencia, la productividad, la calidad, la ejecución presupuestal, la incidencia de la gestión, etc. Estos indicadores entregan señales inequívocas respecto del desempeño y del curso de las estrategias, validándolas o bien mostrando la necesidad de efectuar un ajuste. Anteriormente las organizaciones enfocaban su atención en los indicadores financieros de liquidez, rentabilidad, rotación, endeudamiento, entre otros. Hoy en día las empresas modernas requieren medir los resultados, los procesos, los productos y los servicios de su negocio. En esta relación Olalla (2014) manifiesta que existe una herramienta de gestión, conocida como cuadro de mando integral (BALANCED SCORECARD -BSC-), que va más allá de las medidas financieras e integra las mediciones correspondientes a cuatro áreas. Estas mediciones se enfocan en procesos claves de negocios, y están alineadas con algunos indicadores de desempeño, de manera que la administración es capaz de evaluar rápidamente la salud financiera organizacional a corto y largo plazos. El BSC combina y categoriza las mediciones de los procesos y de resultados en cuatro perspectivas; la del cliente, en los procesos internos, aprendizaje y crecimiento; y el análisis financiero. El BSC constituye un nuevo marco de referencia para evaluar la actividad y los resultados de la organización desde cuatro perspectivas diferentes:

- Financiera: La estrategia del crecimiento, la rentabilidad y el riesgo vista desde la perspectiva del accionista.

- Cliente: La estrategia para crear valor y diferenciación desde la perspectiva del cliente.

- Proceso interno: Las prioridades estratégicas de distintos procesos que crean satisfacción en los clientes y accionistas.

- Aprendizaje y crecimiento: Las prioridades para crear un clima de apoyo al cambio, la innovación y el crecimiento de la organización. (Subía, 2013)

Las áreas funcionales de la empresa, sus metas, objetivos e indicadores se ubican en las diferentes perspectivas del BSC. Por lo tanto, la planificación estratégica, táctica y operativa, se alinea obligatoriamente en un perfil financiero, de procesos, de aprendizaje y del cliente.

\section{Metodología de la auditoría de gestión.}

La metodología de la auditoria de gestión sirve como una guía de actuación para el auditor, de manera que las actividades a realizar en todas sus etapas se conduzcan de manera ordenada y sistémica, delimitar la extensión de los procedimientos a emplear, garantizando el manejo oportuno y objetivo de los resultados. Entre otros aspectos tiende a favorecer al auditor el ordenamiento e identificación de la información, relacionada con la base legal, los hallazgos, evidencias y observaciones para su posterior revisión y seguimiento. De conformidad con la Empresa \& Gestiòn 
reglamentación de auditoría vigente la metodología a seguir para su ejecución implica desarrollar el trabajo en las siguientes fases:

- Planificación

- Ejecución

- Comunicación de resultados

Al respecto Subía (2013) menciona que: "la auditoría siempre incluirá una fase de planificación que nos permita delinear la estrategia a aplicar en las posteriores fases de ejecución y presentación de resultados. En todo caso, el proceso de auditoría siempre será sistemático" (p. 43). La metodología de la auditoria de gestión sirve como una guía de actuación para que el auditor, conduzca de manera ordenada y sistémica todas las actividades a realizar en cada una de las etapas que la conforman, delimite la extensión de los procedimientos a emplear, garantizando el manejo oportuno y objetivo de los resultados.

\section{Planificación de la auditoría de gestión.}

Esta fase implica el desarrollo de una estrategia global para su administración, al igual que el establecimiento de un enfoque apropiado sobre la naturaleza, oportunidad y alcance de los procedimientos de auditoría que deben aplicarse. El desarrollo de una estrategia global en relación con el objetivo y alcance de la auditoría, de acuerdo a Pelazas (2015) hace referencia la necesidad de que el auditor realice los trabajos necesarios para conocer, con carácter previo y de forma completa, los sistemas de control interno de la entidad auditada, cuya evaluación servirá de base para determinar la extensión de las pruebas que se van a efectuar. También señala que realizará y dejará evidencia de la planificación y programación de los trabajos.

Es decir, el primer resultado de esta fase es la enunciación de los objetivos y alcance de la auditoría, que será recogido en un documento formal denominado plan de auditoría. El auditor debe identificar las áreas más importantes, medir el nivel de riesgo y planificar la obtención de la evidencia necesaria para examinar los distintos elementos de la organización objeto del examen. Debe definir dé manera efectiva y eficiente los procedimientos para obtener los datos necesarios e informar acerca de la gestión de la organización. El auditor para obtener información es necesario que se apoye en varios instrumentos como el cuestionario de auditoria, que tiene como finalidad de esclarecer cómo la organización desarrolla los múltiples procesos para cumplir con su objeto social. Esta herramienta permite apoyar la gestión del auditor en el control interno a fin de obtener información y precisar una valoración de la entidad. En este ámbito el cuestionario de control interno, es un instrumento de aproximación a los sistemas de control de la empresa, que permite conocer si la gerencia ha implantado medidas de resguardo de sus recursos y medir la fiabilidad del control interno a nivel global y a nivel de componentes. Los cuestionarios contienen en modelo de pregunta cerrada un texto con elementos de control relacionados, por una parte, con el conocimiento 
de negocio, la organización, los sistemas de información y tecnología, la actitud de la gerencia, etc.; y por otro, con los factores de riesgo que pueden afectar (Velásquez, 2012).

En este contexto, el informe COSO se presenta como un marco de referencia para evaluar el sistema de control interno en la empresa para evaluar su funcionamiento efectivo. De acuerdo a Navarro y Ramos (2016) el informe COSO constituye un modelo de evaluación de las normas, procedimientos y políticas llevadas a cabo por la junta directiva, la gerencia y demás integrantes de la organización, con la finalidad de brindar seguridad razonable con respecto al logro de los objetivos institucionales relacionados con el nivel de eficiencia y efectividad con que se ejecutan las operaciones y actividades corporativas, el grado de fiabilidad que exhibe la información financiera generada por los sistemas de información y el nivel de cumplimiento por parte de la empresa de las disposiciones normativas y estatutarias, se han establecido cinco componentes básicos que se encuentran interrelacionados unos con otros. Los cinco componentes básicos que integran el Informe COSO son: el ambiente de control, evaluación de los riesgos, actividades de control, información y comunicación y seguimiento o monitoreo.

\section{Ejecución o examen de auditoría.}

En la fase de ejecución se aplican los procedimientos de auditoría incluidos los programas de trabajo, representa el cumplimiento de las pruebas para lograr los objetivos que se persiguen en la auditoría, que para el caso de la auditoría de gestión se deberá verificar el logro de las metas, la inversión de los recursos y lo adecuado de la estructura organizacional. Franklin (2007) con respecto al examen de auditoria opina que una vez que se haya puesto en marcha la instrumentación luego de haber seleccionado y aplicado las técnicas de recolección, determinados los instrumentos de medición, iniciada la elaboración de los papeles de trabajo y registradas las evidencias bajo una estricta supervisión, se debe llevar a cabo el examen, el cual consiste en dividir o separar los elementos componentes de los factores bajo revisión. Esta fase inicia con la aplicación de los programas específicos producidos en la planificación, continúa con la obtención de información, la identificación de los hallazgos y las conclusiones por componentes importantes, luego se debe comunicar a la administración de la empresa para resolver los problemas y promover la eficiencia y eficacia de sus operaciones.

Entre los objetivos de la segunda fase de auditoría, se puede sintetizar en los siguientes:

- "Aplicar los programas de trabajo.

- Obtener evidencia total para lograr un juicio sobre la gestión

- Desarrollar los hallazgos de auditoria

- Diseñar y organizar los papeles de trabajo

- Mantener comunicación permanente con la empresa auditada. 
- Aplicación de programas" (León, 2012, p.54).

En esta fase se generan los hallazgos que fundamentarán el informe de auditoría. Los hallazgos de auditoría según Araya (2019) representan aquellas situaciones quer revisten importancia relativa, para la actividad objeto de examen del auditor, que requiere ser documentada y debidamente comprobada. Estos hallazgos deben ser obtenidos mediante la aplicación de procedimientos de auditoría, de acuerdo con las mejores prácticas y patrones de trabajo que se tengan debidamente formalizados en los manuales de trabajo de la auditoría y en la aplicación de las normas que regulan el ejercicio de la profesión. El hallazgo debe ser redactado tomando en cuenta los atributos que lo conforman, es decir la condición, criterio, causa y efecto.

Olalla (2014) en cuanto a los indicadores de gestión define a cada uno de estos atributos de la siguiente manera. La condición es la situación encontrada en la empresa auditada, es decir son los resultados reales y se encuentra plasmada en el indicador. El criterio es lo que debe ser, lo que se pretendió, se planificó o programó, está por lo tanto constituido por el estándar. El efecto es el impacto negativo para la organización y está constituido por la brecha incumplida y que se determina en el índice, o comparación entre lo realizado y lo planificado, es decir entre el indicador y el estándar. La causa es el origen de la desviación entre el indicador y el estándar y se establece al evaluar el proceso para el cumplimiento de objetivo y se logra mediante el análisis del sistema de control interno, para lo cual se utilizan los indicadores de proceso o de actividad.

La etapa de ejecución en la auditoria de gestión es el resultado de la aplicación de indicadores de gestión que demuestran los aspectos examinados y establecen las razones de incumplimiento con respecto a lo planificado, circunstancias que son informadas en la siguiente fase.

\section{Informe de auditoría.}

El informe es el documento que señala los hallazgos del auditor, así como las conclusiones y recomendaciones generadas en relación con los objetivos propuestos para el examen de que se trate. Al término de cada intervención, el titular de la instancia de control debe presentarlo a la autoridad competente, por escrito y con su firma. En la presentación de informes de auditoría se tiene que considerar la forma, el contenido y la distribución de los mismos. (Franklin, 2007). El informe de auditoría, es la manifestación de una opinión profesional, en el que se confirma el resultado del ejercicio de auditoria. Debe abarcar la evaluación del control interno, el cumplimiento de las normas y procedimientos a los que se encuentra regida la organización y otros aspectos relacionados con la gestión. Las opiniones contenidas en el informe deben estar soportadas en hallazgos, la calidad de los mismos y de las recomendaciones posiciona o debilita la evaluación ante la organización. 


\section{Metodologia.}

La investigación se desarrolló bajo un diseño experimental mediante la ejecución de una auditoria de gestión en la empresa Multimotos S.A, a efecto de evaluar la eficiencia y eficacia de la organización, en tal razón, se realizó la manipulación de la variable independiente para determinar su incidencia sobre las variables dependientes. Considerando el contexto de la investigación se aplicaron procesos sistémicos empíricos y críticos para la recolección y análisis de datos cuantitativos y cualitativos. En cuanto al alcance el estudio fue descriptivo - explicativo ya que en la primera fase de la investigación se especificaron las propiedades y características de las variables de estudio y se recogió y evaluó los datos cualitativos en un solo momento del tiempo mediante la aplicación de cuestionarios, entrevistas y revisión documental mientras que, en una segunda fase caracterizo el fenómeno de estudio en la unidad de análisis identificando ciertos rasgos de elementos de interés relacionados con el control interno, la eficiencia y la eficacia organizacional.

Los métodos empleados fueron el inductivo - deductivo, mediante el cual se analizaron los principios generales de la auditoria de gestión y se derivaron conclusiones específicas. El método analítico - sintético sustentado en norma y procedimientos permitió la identificación del problema, sus causas generadoras, forma de existencia, los procesos, procedimientos y de conexiones internas y externas de la empresa Multimotos S.A.; el método estadístico permitió la obtención, representación, simplificación e interpretación de los resultados obtenidos.

\section{Ejecución de la Auditoría de Gestión}

\section{Conocimiento preliminar (fase I)}

\section{Antecedentes}

Multimotos S.A., se constituye como empresa el 23 de noviembre de 2011, iniciando con 7 agencias en enero del 2012, que a la actualidad mantenemos 35 agencias operativas. La empresa se formó con el concepto de multimarca que se mantiene hasta la actualidad, dando mayor participación a las marcas del Grupo Vázquez (motor 1, Sukida, TVS).

\section{- Socios}

La empresa se encuentra constituida por 3 accionistas conforme se explica en la tabla 1:

Tabla 1. Resumen de accionistas de la empresa

\begin{tabular}{ccc}
\hline No & Nombre & Nacionalidad \\
\hline 1 & Impritsa S.A & Ecuador \\
2 & Vazpro S.A & Ecuador \\
3 & Zabala Goetschel & Ecuador \\
\hline
\end{tabular}




\title{
- Empleados
}

La empresa cuenta con 194 colaboradores, distribuidos en 35 agencias, quienes han formado un equipo altamente calificado y comprometido con las metas trazadas por la organización. Clientes, productos y mercado. Es política de la empresa ofrecer un producto de calidad y con una excelente atención, lo que ha generado un impacto positivo, pues se percibe un nivel de satisfacción del cliente y un mayor posicionamiento en el mercado, a razón de encontrarse actualmente en el puesto 37 en el ranking de 100 empresas que han demostrado un crecimiento significativo en el Ecuador. Proveedores. La empresa consiente de que el abastecimiento es parte fundamental del negocio, dispone de una base de datos de proveedores dedicados a la importación y ensamblaje de motos, los mismos han sido seleccionados en función de la calidad, precio y condiciones de pago que ofrecen. Programas de auditoria. Dentro de esta etapa se re realizo lo siguiente Motivo del examen. La auditoría integral a efectuarse en la empresa "Multimotos S.A.", se realizará en cumplimiento de la orden de trabajo 001-AG-JC, del 04 de febrero del 2019 el mismo que se orientará a la evaluación de la eficiencia en el uso de los recursos, eficacia en el cumplimiento de las metas trazadas y al nivel de satisfacción de los clientes.

\section{Objetivo del examen}

Realizar una auditoría de gestión que propicie el mejoramiento de la eficiencia y eficacia organizativa en la empresa "Multimotos" S.A., de la ciudad de Cuenca.

\begin{abstract}
Alcance
La evaluación comprenderá el análisis de los objetivos planteados por la empresa, así como de los recursos utilizados en la consecución de los mismos durante el periodo comprendido entre el 1 de enero y 31 de diciembre del 2018. Base legal. De acuerdo a la Súper Intendencia de compañías en la ciudad de Cuenca ante el notario noveno el 23 de noviembre del 2011 se da la constitución de la empresa Multimotos S.A de la ciudad de cuenca con el memorándum número SC.UJ.C.2011.509
\end{abstract}

\section{Normativa externa a la que se encuentra regida}

- Servicio de Rentas Internas. (SRI)

- Instituto Ecuatoriano de Seguridad Social (IEES)

- Super intendencia de compañías 


\section{Estructura orgánica}

\section{ORGANGGAMNA MASTERMOTOS.A.}

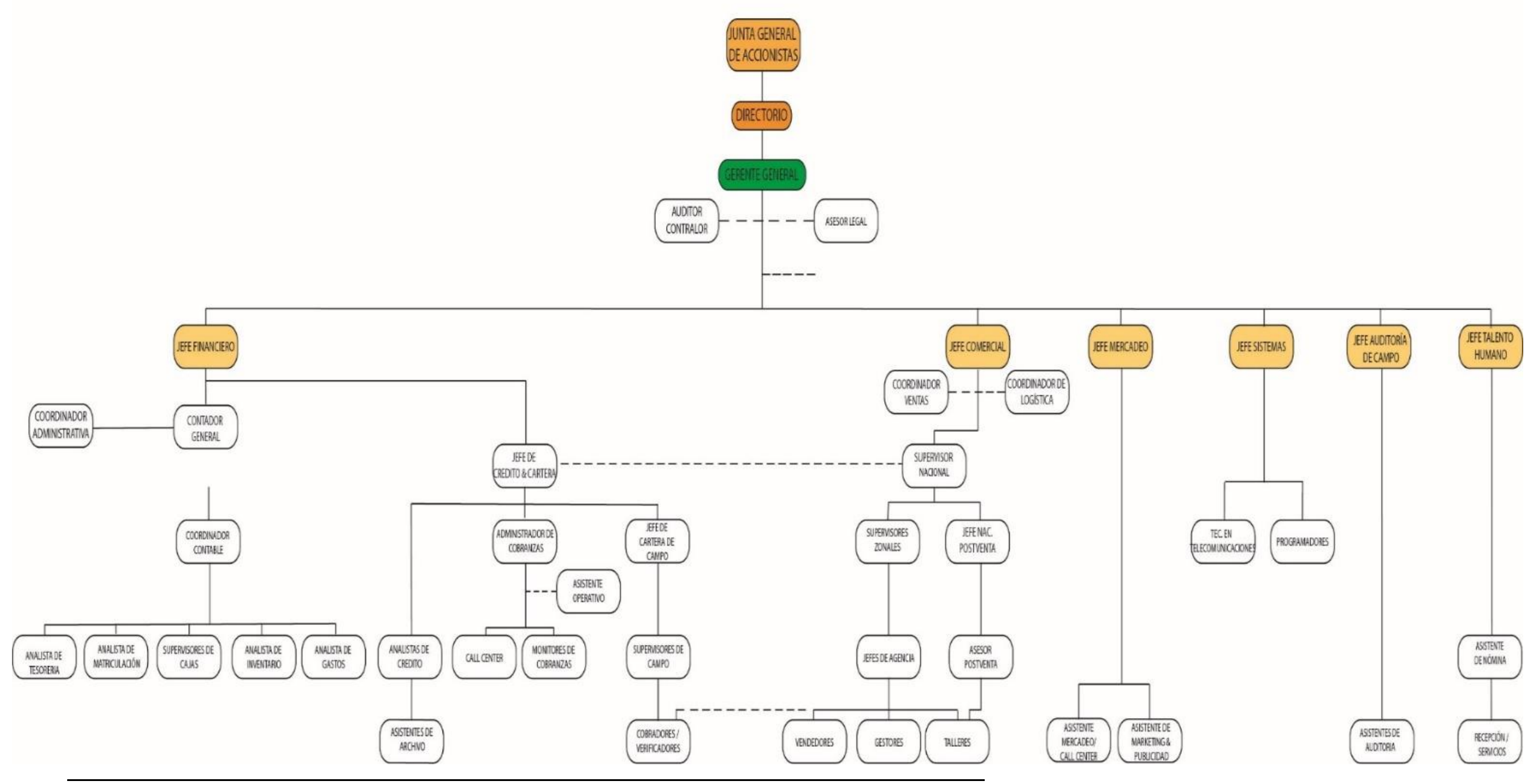




\section{Misión y Objetivos Institucionales}

Misión. Satisfacer la necesidad de movilidad con la comercialización de motocicletas óptimas en calidad y prestaciones para el mercado ecuatoriano, brindando un servicio de calidad que sobrepase las expectativas y necesidades de nuestros clientes. Visión Ser líderes en la comercialización de motocicletas en el mercado ecuatoriano, diferenciándonos en el servicio al cliente y un respaldo post venta, basado en valores corporativos y responsabilidad social.

\section{Objetivos Institucionales}

- Llegar a consolidarnos en el mercado ecuatoriano como la cadena líder de almacenes de venta de motocicletas, diferenciándonos por disponibilidad de repuestos y respaldo técnico.

- Ampliar la cobertura geográfica mediante la apertura de nuevas tiendas en lugares estratégicos que contribuyan al crecimiento de la empresa.

- Mantener el desarrollo y mejoramiento continuo de los procesos de selección de su personal para que se integre con entusiasmo a los desafíos de la organización y el mercado.

- Cumplir las leyes y obligaciones tributarias con puntualidad actuando siempre con los valores corporativos.

- Mantener un mejoramiento continuo de los procesos de venta y generación de crédito para lograr la satisfacción de nuestros clientes motivando la recompra de productos y servicios

\section{Funciones}

De acuerdo a la magnitud del manual de funciones se expone un ejemplar.

\section{Gerente general}

Direccionar los procesos en la compañía para dar cumplimiento a los objetivos propuestos buscando su fortalecimiento y crecimiento, destinando recursos para tal fin.

Liderar la gestión estratégica, dirigiendo y coordinando a las distintas áreas para asegurar la rentabilidad, competitividad, continuidad y sustentabilidad de la empresa, cumpliendo con los lineamientos estratégicos del directorio y las normativas y reglamentos vigentes.

\section{Responsabilidades del cargo}

- Ejercer la representación legal de la Empresa.

- Realizar la administración global de las actividades de la empresa buscando su mejoramiento organizacional, técnico y financiero. 
- Garantizar el cumplimiento de las normas, reglamentos, políticas e instructivos internos y los establecidos por las entidades de regulación y control.

- Participar en reuniones con el Directorio, para analizar y coordinar las actividades de la empresa en general.

- Coordinar y controlar la ejecución y seguimiento al cumplimiento del Plan Estratégico.

- Participar en reuniones en general.

\section{Finanzas y administración}

- Controlar y supervisar los reportes financieros, comparando resultados reales con los presupuestados.

- Controlar la administración de los recursos monetarios y el cumplimiento de regulaciones en materia tributaria, arancelaria y demás obligaciones legales.

- Controlar los costos y rentabilidad de la empresa.

- Administrar los presupuestos operacionales y las inversiones de la empresa de acuerdo a lo resuelto por el Directorio.

- Gestión de Compras

- Controlar los niveles de inventarios.

- Gestión financiera estratégica.

\section{Comercialización}

- Controlar el cumplimiento de los planes y programas de comercialización.

- Controlar que los índices y costos de comercialización.

- Controlar los movimientos de las agencias.

- Manejo de Proyectos de Inversión

\section{Ventas y mercadeo}

- Diseñar y desarrollar estrategias tendientes a incrementar la rentabilidad y participación en el mercado nacional.

- Definir las políticas de ventas.

- Supervisar la planificación y ejecución de las estrategias y acciones de comercialización de la empresa.

- Efectuar el análisis y evaluación de los resultados de los planes de mercadeo y ventas de la empresa.

- Supervisar la rotación de los productos de la empresa.

- Controlar los niveles de cartera.

- Realizar visitas a clientes claves y/o Agencias. 


\section{Servidores relacionados.}

Tabla 2. Servidores relacionados con el examen

\begin{tabular}{lllll}
\hline \multirow{2}{*}{ Nombres } & \multirow{2}{*}{ Apellidos } & \multicolumn{1}{c}{ Cargo } & \multicolumn{2}{c}{ Periodo de actuación } \\
Desde & Hasta \\
\hline Alfredo Antonio & Vega Escudero & Gerente & 21 de enero del 2011 & Continua \\
Juan Diego & Campoverde & Gerente Financiero & 10 de julio del 2016 & Continua \\
Henry & Pacheco & Gerente Comercial & 24 de mayo del 2015 & Continua \\
Soledad Burbano & & Jefe de Talento & 11 de septiembre del 2018 & Continua \\
\hline
\end{tabular}

\section{Grado de confiabilidad de la información financiera, administrativa y operacional}

La información que genera la empresa, producto de sus operaciones empresariales son archivadas adecuadamente en los distintos departamentos, los mismos cuentan con la documentación necesaria que garantiza la legalidad y veracidad de las transacciones que realiza cotidianamente

El sistema contable que maneja la empresa se llama Ecuasof y genera la siguiente información financiera en función de los requerimientos de los socios y de los organismos de control:

- Estado de resultados

- Estado de situación financiera

- Estado de flujo del efectivo

- Reporte de compras, ventas

\section{Componentes y subcomponentes a ser examinados}

Sistema de control interno y sus componentes de acuerdo al informe COSO:

- Ambiente de control

- Evaluación de los riesgos

- Actividades de control

- Información y comunicación

- Monitoreo 
Tabla 3. Evaluación al sistema de control interno - Ambiente de control.

\section{Empresa Multimotos S.A.}

Evaluación al sistema de control interno, relacionado con la aplicación de la normas de control interno

\begin{tabular}{|c|c|c|c|c|c|}
\hline \multicolumn{6}{|c|}{ Periodo : enero 2018 diciembre 2018} \\
\hline \multicolumn{3}{|c|}{ componentes COSO } & \multicolumn{2}{|c|}{ respuesta } & \multirow{2}{*}{ comentarios } \\
\hline 200 & componente: ambiente de control & pt & si/no & calif. & \\
\hline $200-1$ & integridad y valores éticos & 1 & & 1 & \\
\hline 1 & $\begin{array}{l}\text { ¿se han establecido principios y valores éticos como parte de la } \\
\text { cultura organizacional? }\end{array}$ & 1 & si & 1 & por escrito no \\
\hline $200-2$ & Administración estratégica & 5 & & 1 & \\
\hline 1 & ¿Se ha definido la misión y visión de la entidad? & 1 & $\mathrm{Si}$ & 1 & \\
\hline 2 & ¿La entidad posee un plan operativo anual? & 1 & No & 0 & \\
\hline 3 & $\begin{array}{l}\text { ¿El plan operativo anual contiene: objetivos, indicadores, metas, } \\
\text { programas, proyectos y actividades que se impulsarán en el período } \\
\text { anual? }\end{array}$ & 1 & No & 0 & \\
\hline 4 & $\begin{array}{l}\text { ¿Se realiza un seguimiento y evaluación permanente del POA y } \\
\text { Planes Plurianuales? }\end{array}$ & 1 & No & 0 & \\
\hline 5 & $\begin{array}{l}\text { ¿Los productos de la formulación, cumplimiento, seguimiento y } \\
\text { evaluación del plan plurianual y POA fueron difundidos a todo el } \\
\text { personal de la entidad y comunidad en general? }\end{array}$ & 1 & No & 0 & \\
\hline $200-3$ & Políticas y Prácticas de Talento Humano & 5 & & 3 & \\
\hline 1 & $\begin{array}{l}\text { ¿Se establecen necesidades de capacitación del recurso humano y } \\
\text { su respectiva programación? }\end{array}$ & 1 & si & 1 & \\
\hline 2 & $\begin{array}{l}\text { ¿La Dirección de RRHH efectúa el reclutamiento de personal que } \\
\text { labora en la entidad acorde con el cumplimiento de los requisitos } \\
\text { establecidos?? }\end{array}$ & 1 & si & 1 & \\
\hline 3 & $\begin{array}{l}\text { ¿Se establecen mallas curriculares para la detección de las } \\
\text { necesidades de capacitación del recurso humano y su respectiva } \\
\text { programación? }\end{array}$ & 1 & No & 0 & \\
\hline 4 & $\begin{array}{l}\text { ¿La dirección de RRHH realiza la evaluación al rendimiento o } \\
\text { desempeño de las funciones de los empleados de la empresa por lo } \\
\text { menos dos veces al año?? }\end{array}$ & 1 & No & 0 & \\
\hline 5 & $\begin{array}{l}\text { ¿La dirección de RRHH aplica los principios de justicia y equidad } \\
\text { en todos sus procesos de clasificación, reclutamiento y selección } \\
\text { del personal, capacitación, evaluación del desempeño y } \\
\text { promoción?? }\end{array}$ & 1 & si & 1 & \\
\hline $200-4$ & Estructura Organizativa & 1 & & 1 & \\
\hline 1 & $\begin{array}{l}\text { ¿Posee la institución un Manual de descripción, valoración y } \\
\text { clasificación de puestos? }\end{array}$ & 1 & $\mathrm{Si}$ & 1 & \\
\hline $200-8$ & Adhesión a las políticas Institucionales & 1 & & 1 & \\
\hline 1 & $\begin{array}{l}\text { ¿La máxima autoridad establece políticas institucionales y } \\
\text { específicas aplicables a las áreas de trabajo? }\end{array}$ & 1 & $\mathrm{Si}$ & 1 & \\
\hline
\end{tabular}


Tabla 4. Evaluación al sistema de control interno - Evaluación del Riesgo

\section{Empresa Multimotos S.A.}

Evaluación al sistema de control interno, relacionado con la aplicación de la normas de control interno

\begin{tabular}{|c|c|c|c|c|c|}
\hline \multicolumn{6}{|c|}{ Periodo : enero 2018 diciembre 2018} \\
\hline \multicolumn{3}{|c|}{ Componentes COSO } & \multicolumn{2}{|c|}{ respuesta } & \multirow{2}{*}{ Comentarios } \\
\hline 300 & componente: evaluación del riesgo & pt & si/no & calif. & \\
\hline 300-01 & Identificación de Riesgos & 1 & & 1 & \\
\hline 1 & $\begin{array}{l}\text { ¿La máxima autoridad identifica los riesgos que afectan el logro de } \\
\text { los objetivos considerando los factores internos o externos? }\end{array}$ & 1 & si & 1 & \\
\hline 300-02 & Plan de Mitigación de Riesgos & 1 & & 1 & \\
\hline 1 & $\begin{array}{l}\text { ¿Existe un Plan de Mitigación de Riesgos desarrollado y } \\
\text { documentado con una estrategia clara, organizada e interactiva para } \\
\text { identificar y valorar los riesgos que puedan impactar en la entidad } \\
\text { impediendo el logro de sus objetivos? }\end{array}$ & 1 & $\mathrm{Si}$ & 1 & \\
\hline & & & & & \\
\hline 300-03 & Valoración de los Riesgos & 1 & & 1 & \\
\hline 1 & $\begin{array}{l}\text { ¿Se cuenta con un estudio detallado de los temas puntuales sobre } \\
\text { riesgos que se hayan decidido evaluar que permita a las servidoras o } \\
\text { servidores reflexionar sobre cómo los riesgos pueden afectar el logro } \\
\text { de sus objetivos? }\end{array}$ & 1 & $\mathrm{Si}$ & 1 & \\
\hline
\end{tabular}

Tabla 5. Evaluación al sistema de control interno - Actividades de Control

\section{Empresa Multimotos S.A.}

Evaluación al sistema de control interno, relacionado con la aplicación de la normas de control interno

\begin{tabular}{|c|c|c|c|c|c|}
\hline \multicolumn{6}{|c|}{ Periodo : enero 2018 diciembre 2018} \\
\hline \multicolumn{3}{|c|}{ Componentes COSO } & \multicolumn{2}{|c|}{ respuesta } & \multirow{2}{*}{ comentarios } \\
\hline 400 & Componente: actividades de control & pt & si/no & calif. & \\
\hline 401-01 & Separación de funciones y rotación de labores & 2 & & 1 & \\
\hline 1 & ¿Se han definido las funciones de cada servidor por escrito? & 1 & no & 0 & \\
\hline 2 & ¿Se han rotado las tareas y funciones de los servidores? & 1 & si & 1 & \\
\hline 401-02 & Autorización y aprobación de transacciones y operaciones & 1 & & 1 & \\
\hline 1 & $\begin{array}{l}\text { ¿Se ha definido por escrito o por medio de sistemas } \\
\text { electrónicos los procedimientos de autorización que asegure la } \\
\text { ejecución de los procesos y control de las operaciones } \\
\text { administrativas y financieras? }\end{array}$ & 1 & si & 1 & \\
\hline & & & & & \\
\hline 401-03 & Supervisión & 1 & & $\mathbf{0}$ & \\
\hline 1 & $\begin{array}{l}\text { ¿Existen procedimientos e índices que permitan medir la } \\
\text { eficacia y eficiencia de los objetivos institucionales? }\end{array}$ & 1 & no & 0 & \\
\hline 402-02 & Control previo al compromiso & 1 & & 1 & \\
\hline
\end{tabular}




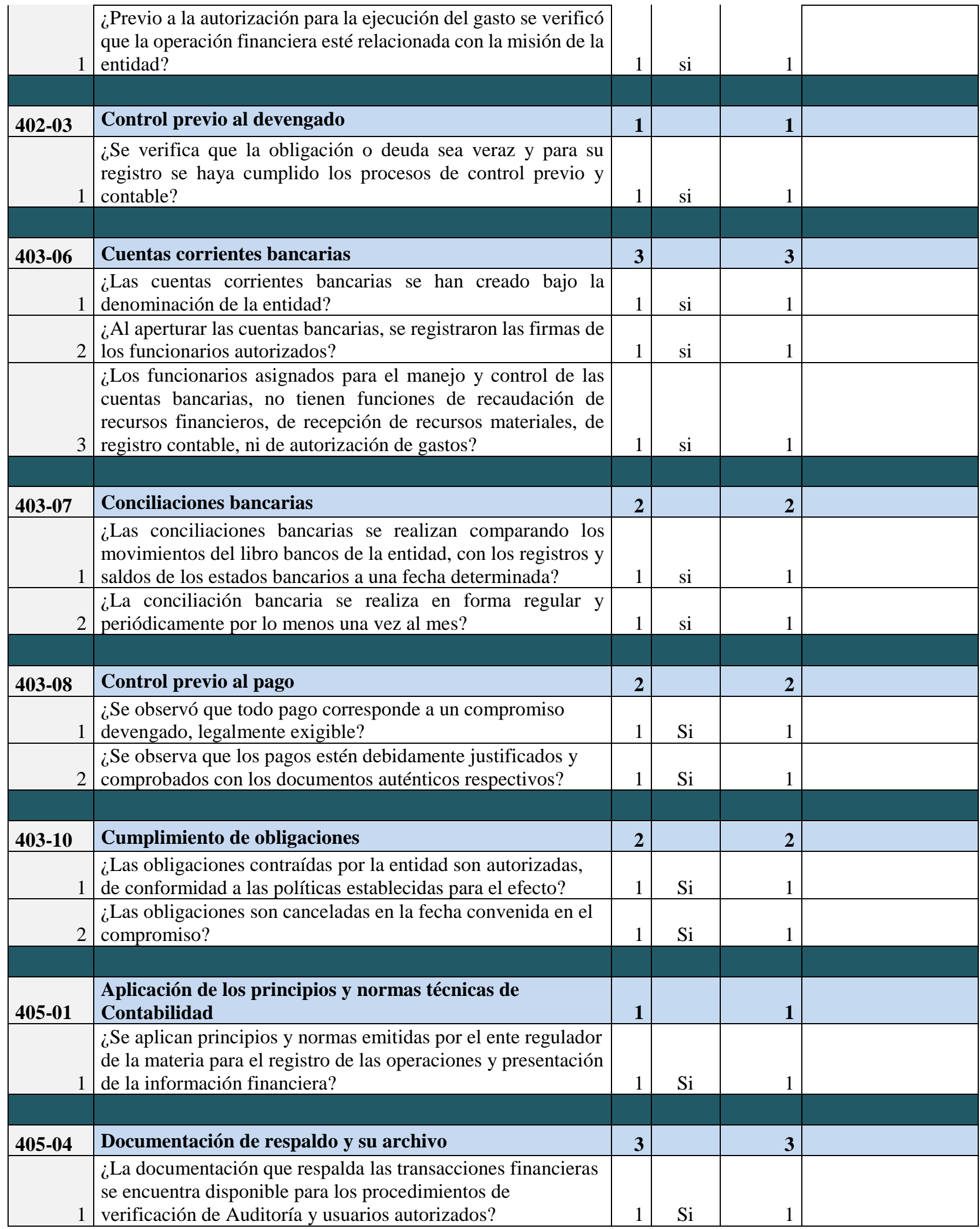


¿Las operaciones financieras están sustentadas con la documentación suficiente que sustente su propiedad, legalidad

2 y veracidad de los mismos?

¿Existe un archivo en orden cronológico y secuencial que permita la conservación y custodia de la documentación financiera por el tiempo fijado por las disposiciones legales

3 vigentes?

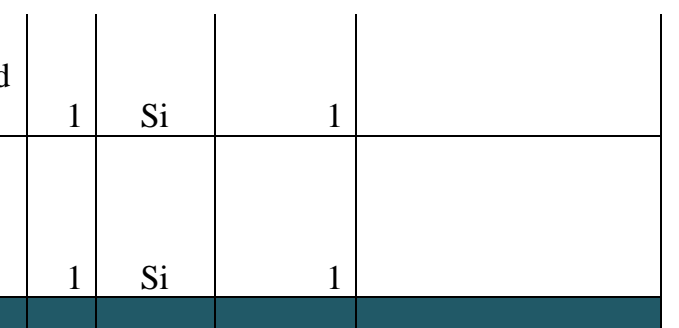

\begin{tabular}{|c|c|c|c|c|}
\hline 405-07 & Formularios y documentos & 3 & & 3 \\
\hline 1 & $\begin{array}{l}\text { ¿Los formularios que se utilizan para el manejo de recursos } \\
\text { materiales y financieros son preimpresos y prenumerados? }\end{array}$ & 1 & $\mathrm{Si}$ & 1 \\
\hline 2 & $\begin{array}{l}\text { ¿Los documentos prenumerados son enumerados en orden } \\
\text { correlativo y cronológico que posibilite un adecuado control? }\end{array}$ & 1 & $\mathrm{Si}$ & 1 \\
\hline 3 & $\begin{array}{l}\text { ¿Cuándo el formulario numerado, es erróneo, se anulada y } \\
\text { archiva el original y las copias respetando su secuencia } \\
\text { numérica? }\end{array}$ & 1 & $\mathrm{Si}$ & 1 \\
\hline
\end{tabular}

\begin{tabular}{|r|l|r|r|r|}
\hline 406-10 & $\begin{array}{l}\text { Constatación física de existencias y bienes de larga } \\
\text { duración }\end{array}$ & $\mathbf{1}$ & & $\mathbf{1}$ \\
\hline & $\begin{array}{l}\text { ¿Cuenta la institución con reglamentación interna en la cual se } \\
\text { definan los procedimientos para la realización de } \\
\text { constataciones físicas periódicas de las existencias y bienes de }\end{array}$ & & & \\
1 & Larga Duración? & $\mathrm{Si}$ & 1 & \\
\hline
\end{tabular}

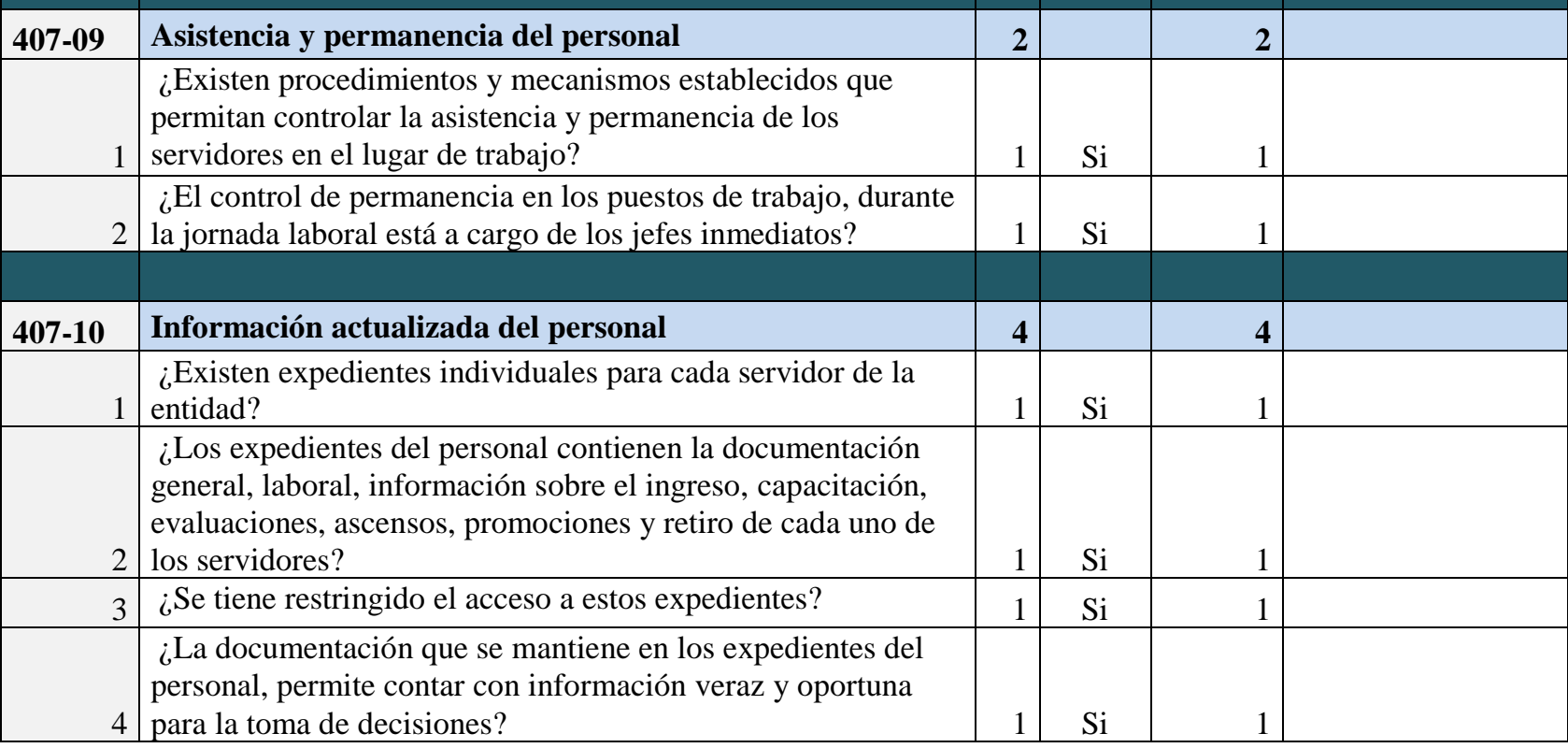


Tabla 6. Evaluación al sistema de control interno - Información y comunicación

\begin{tabular}{|c|c|c|c|c|c|}
\hline \multicolumn{6}{|c|}{ Empresa Multimotos S.A. } \\
\hline \multirow{2}{*}{\multicolumn{6}{|c|}{$\begin{array}{c}\text { Evaluación al sistema de control interno, relacionado con la aplicación de } \\
\text { Periodo: enero } 2018 \text { diciembre } 2018\end{array}$}} \\
\hline & & & & & \\
\hline \multicolumn{3}{|c|}{ Componentes COSO } & \multicolumn{2}{|c|}{ respuesta } & \multirow{2}{*}{ comentarios } \\
\hline 500 & Componente: información y comunicación & pt & si/no & calif. & \\
\hline $500-2$ & Canales de comunicación abiertos & 2 & & 2 & \\
\hline 1 & $\begin{array}{l}\text { ¿Se han establecido canales de comunicación abiertos que } \\
\text { permitan trasladar la información de manera segura, correcta y } \\
\text { oportuna a los destinatarios, así como permita a los usuarios } \\
\text { aportar información sobre el diseño y la calidad de los productos y } \\
\text { servicios brindados? }\end{array}$ & 1 & si & 1 & \\
\hline 2 & $\begin{array}{l}\text { ¿La política de comunicación interna permite las diferentes } \\
\text { interacciones entre los funcionarios? }\end{array}$ & 1 & $\mathrm{Si}$ & 1 & \\
\hline
\end{tabular}

Tabla 7. Evaluación al sistema de control interno - Seguimiento

\begin{tabular}{|c|c|c|c|c|c|}
\hline \multicolumn{6}{|c|}{ Empresa Multimotos S.A. } \\
\hline \multicolumn{6}{|c|}{ Periodo : enero 2018 diciembre 2018} \\
\hline \multicolumn{3}{|c|}{ componentes COSO } & \multicolumn{2}{|c|}{ respuesta } & \multirow{2}{*}{ comentarios } \\
\hline 600 & componente: seguimiento & pt & si/no & calif. & \\
\hline $600-01$ & Seguimiento continuo o en operación & 1 & & 1 & \\
\hline 1 & $\begin{array}{l}\text { ¿Se ha realizado un seguimiento constante del ambiente interno y externo que le } \\
\text { permita conocer y aplicar medidas oportunas sobre condiciones reales o potenciales } \\
\text { que afecten el desarrollo de las actividades institucionales? }\end{array}$ & 1 & si & 1 & \\
\hline $600-02$ & Evaluaciones periódicas & 1 & & 0 & \\
\hline 1 & $\begin{array}{l}\text { ¿Se han establecido evaluaciones periódicas de la gestión y el control interno con el fin } \\
\text { de identificar las fortalezas y debilidades? }\end{array}$ & 1 & no & 0 & \\
\hline
\end{tabular}




\section{Ejecución Fase II}

\section{Papel de trabajo}

Tabla 8. Cedula narrativa.

\begin{tabular}{|c|c|c|}
\hline Del 1 & 2018 & PT.AG.1 \\
\hline & $(\mathrm{CN})$ & \\
\hline $\begin{array}{l}\text { EL día } 12 \text { de mayo del año } 2019 \text { se a } \\
\text { empresa Multimotos quien brindó s } \\
\text { entrevista obtuvimos la siguiente info } \\
\text { - No cuenta con un plan estrat } \\
\text { - } \\
\text { - } \\
\text { - } \\
\text { No cuenta con conta con indicadorates d } \\
\text { No existe segregación de fun }\end{array}$ & $\begin{array}{l}\text { control interno al In } \\
\text { desarrollo de la auc }\end{array}$ & $\begin{array}{l}\text { gerente de la } \\
\text { ultados de la }\end{array}$ \\
\hline Realizado por: Juan Carlos castillo & Supervisado por: & \\
\hline Fecha: 12 de mayo del 2019 & Fecha: & \\
\hline
\end{tabular}

\section{Resultados fase III.}

El procedimiento a seguir para la ejecución de la auditoria de gestión consistió en la revisión en forma sistemática y ordenada, la misma que inició con una verificación documental de las actividades principales de la empresa, para ubicar exactamente la extensión del trabajo a desarrollar, se revisó el adecuado funcionamiento del sistema de control interno, así como el nivel de eficiencia y eficacia en la utilización de los recursos disponibles. La ejecución del examen implicó acumular evidencia con la finalidad de descubrir las inconformidades. El estudio realizado exigió la utilización de requerimientos de investigación bibliográfica mediante la recopilación información proveniente de libros y artículos científicos, el trabajo fue intencional y se desarrolló bajo los criterios de la auditoría de gestión, que se orienta a la evaluación de la eficiencia, eficacia y calidad de los productos y servicios proporcionados por una empresa. Para la evaluación del control interno, de acuerdo a lo descrito en los párrafos anteriores el informe COSO constituye un modelo de evaluación aplicable a toda organización ya sea esta pública o privada. El cuestionario de control interno se aplicó al 
Gerente General, Gerente Comercial, Gerente Financiero y Jefe de Talento Humano, como responsables de las áreas más relevantes de la empresa. Las preguntas fueron distribuidas de acuerdo a los componentes del control interno y considerando las funciones de cada uno.

Debido a que la empresa no dispone de planificación estratégica y por ende carece de indicadores, se diseñó indicadores de gestión en conformidad con las perspectivas financiera, clientes, procesos internos y aprendizaje y crecimiento. Para finalizar, se aplicó una encuesta a 96 clientes con el objetivo de medir su nivel de satisfacción.

Con base a la evidencia obtenida, se evaluó la efectividad del sistema de control interno de la empresa en cada uno de los siguientes componentes: ambiente de control, evaluación de los riesgos, actividades de control, información y comunicación y monitoreo, así como establecer el nivel de confianza y riesgo de control para determinar la naturaleza y alcance de los procedimientos de auditoría a aplicar en la fase de ejecución de la auditoría.

Al respecto se establece los siguientes resultados:

Tabla 9. Resumen de la evaluación del sistema de control interno

\begin{tabular}{|c|c|c|c|c|c|c|}
\hline \multicolumn{2}{|r|}{ Componente } & CT & PT & $\mathrm{NC}$ & RI & $\begin{array}{l}\text { NIVEL DE } \\
\text { RIESGO }\end{array}$ \\
\hline \multicolumn{7}{|c|}{ Ambiente de control } \\
\hline $200-1$ & Integridad y valores éticos & 1 & 1 & $100 \%$ & $0 \%$ & bajo \\
\hline $200-2$ & Administración estratégica & 1 & 5 & $20 \%$ & $80 \%$ & alto \\
\hline $200-3$ & Políticas y Prácticas de Talento Humano & 3 & 5 & $60 \%$ & $40 \%$ & moderado \\
\hline $200-4$ & Estructura Organizativa & 1 & 1 & $100 \%$ & $0 \%$ & bajo \\
\hline $200-8$ & Adhesión a las políticas Institucionales & 1 & 1 & $100 \%$ & $0 \%$ & bajo \\
\hline \multicolumn{7}{|c|}{ evaluación del riesgo } \\
\hline $300-01$ & Identificación de Riesgos & 1 & 1 & $100 \%$ & $0 \%$ & bajo \\
\hline $300-02$ & Plan de Mitigación de Riesgos & 1 & 1 & $100 \%$ & $0 \%$ & bajo \\
\hline $300-03$ & Valoración de los Riesgos & 1 & 1 & $100 \%$ & $0 \%$ & bajo \\
\hline \multicolumn{7}{|c|}{ actividades de control } \\
\hline 401-01 & Separación de funciones y rotación de labores & 1 & 2 & $50 \%$ & $50 \%$ & alto \\
\hline 401-02 & $\begin{array}{l}\text { Autorización y aprobación de transacciones y } \\
\text { operaciones }\end{array}$ & 1 & 1 & $100 \%$ & $0 \%$ & bajo \\
\hline $401-03$ & Supervisión & 0 & 1 & $0 \%$ & $100 \%$ & alto \\
\hline $402-02$ & Control previo al compromiso & 1 & 1 & $100 \%$ & $0 \%$ & bajo \\
\hline $402-03$ & Control previo al devengado & 1 & 1 & $100 \%$ & $0 \%$ & bajo \\
\hline $403-06$ & Cuentas corrientes bancarias & 3 & 3 & $100 \%$ & $0 \%$ & bajo \\
\hline $403-07$ & Conciliaciones bancarias & 2 & 2 & $100 \%$ & $0 \%$ & bajo \\
\hline $403-08$ & Control previo al pago & 2 & 2 & $100 \%$ & $0 \%$ & bajo \\
\hline $403-10$ & Cumplimiento de obligaciones & 2 & 2 & $100 \%$ & $0 \%$ & bajo \\
\hline $405-01$ & $\begin{array}{l}\text { Aplicación de los principios y normas técnicas de } \\
\text { Contabilidad }\end{array}$ & 1 & 1 & $100 \%$ & $0 \%$ & bajo \\
\hline $405-04$ & Documentación de respaldo y su archivo & 3 & 3 & $100 \%$ & $0 \%$ & bajo \\
\hline
\end{tabular}




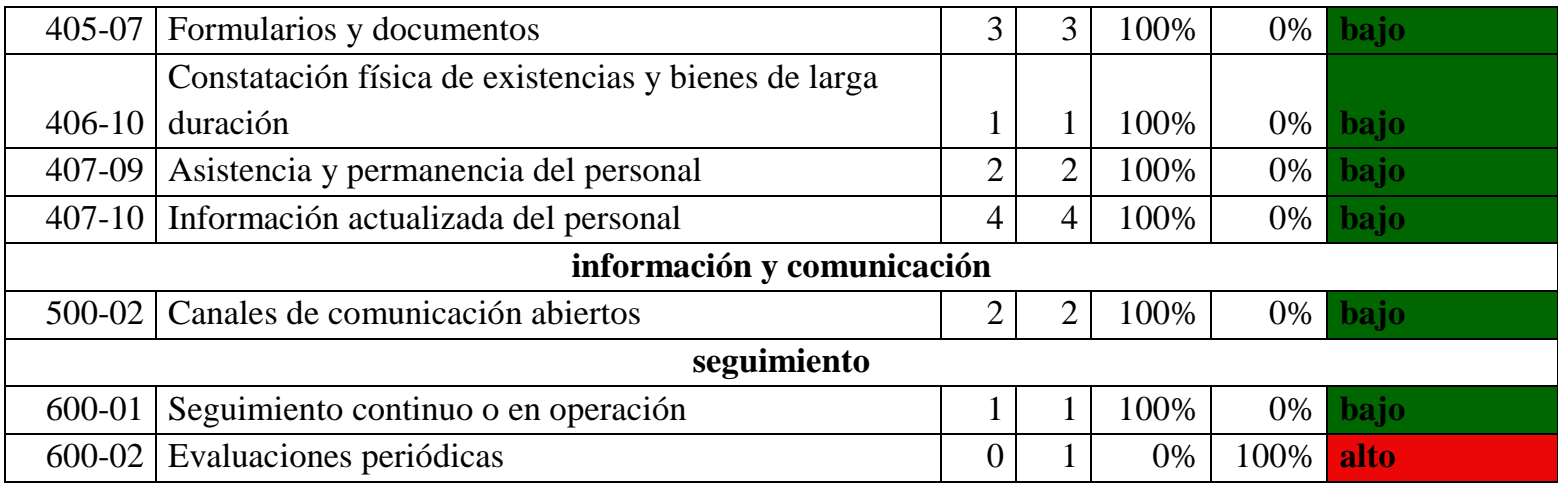

El nivel de confianza y riesgo del sistema de control interno se evidencia en la tabla 10

Tabla 10. Nivel de confianza y riego del sistema de control interno

Tabla del nivel de confianza

$\begin{aligned} 76 \text { al } 95 \% & =\text { alto } \\ 51 \text { al } 75 \% & =\text { moderado } \\ 15 \text { al } 50 \% & =\text { bajo }\end{aligned}$

Nivel de confianza $=\mathrm{CT} / \mathrm{PT}$

\begin{tabular}{|rr} 
Calificación total - CT & $\mathbf{4 0}$ \\
Ponderación total - PT & $\mathbf{4 9}$ \\
Nivel de confianza & $\mathbf{8 2 \%}$ \\
Nivel confianza - N/C & Alta \\
Nivel de riesgo -N/R & Bajo
\end{tabular}

Las inconformidades encontradas a través de la aplicación del cuestionario de control interno refieren a procedimientos o aspectos que la empresa no aplica de manera adecuada o no dispone, entre ellos se encontró los siguientes:

- La institución no dispone de una planificación estratégica.

- No cuenta con políticas y prácticas de talento humano,

- No existe separación de funciones,

- La gerencia de la empresa no ha definido procedimientos de supervisión de los procesos y operaciones, que aseguren el cumplimiento de las normas y regulaciones.

- No ha establecido evaluaciones periódicas de la gestión y el control interno,

- En relación a la aplicación de indicadores de gestión para medir el cumplimiento de las metas establecidas en la empresa se determinó el siguiente grado de eficacia:

Tabla 11. Grado de eficacia en el cumplimiento de las metas programadas

\begin{tabular}{l|rrrr}
\multicolumn{1}{c|}{ Nombre del indicador } & Estándar & Ejecutado & \multicolumn{1}{c}{ Cálculo } & Brecha \\
& & & $\begin{array}{c}\text { Ejecutado/ } \\
\text { estándar }\end{array}$ & \\
\hline $\begin{array}{l}\text { Porcentaje de liquidez incrementada en el año } \\
\text { 2018. }\end{array}$ & $2 \%$ & $2.00 \%$ & $100.00 \%$ & $0.00 \%$ \\
\hline $\begin{array}{l}\text { Porcentaje de cuentas incobrables disminuidas en } \\
\text { el año 2018. }\end{array}$ & $25 \%$ & $25.00 \%$ & $100.00 \%$ & $0.00 \%$ \\
\hline $\begin{array}{l}\text { Porcentaje de clientes de la empresa satisfechos en } \\
\text { el año 2018. }\end{array}$ & $100 \%$ & $83.33 \%$ & $83.33 \%$ & $16.67 \%$ \\
\hline
\end{tabular}


ISSN: 2602-8506

Vol. 3, N².1., p. 159-188, junio, 2019

\begin{tabular}{l|cccc}
\hline $\begin{array}{l}\text { Porcentaje de volumen de ventas incrementadas } \\
\text { en el año 2018. }\end{array}$ & $15 \%$ & $12 \%$ & $80.00 \%$ & $20.00 \%$ \\
\hline $\begin{array}{l}\text { Porcentaje de incremento de personal capacitado } \\
\text { en el año 2018 }\end{array}$ & $70 \%$ & $66.67 \%$ & $95.24 \%$ & $4.76 \%$ \\
$\begin{array}{l}\text { Promedio de metas cumplidas } \\
\text { Prome }\end{array}$ & & $\mathbf{9 1 . 7 1 \%}$ & $\mathbf{8 . 2 9 \%}$
\end{tabular}

Como se puede apreciar el nivel de cumplimiento de la empresa con respecto a las metas programadas es del $91.71 \%$, por lo que, se requiere motivar y empoderar al personal para alcanzar en un $100 \%$ las metas y objetivos empresariales.

Al analizar el nivel de eficiencia alcanzado en la utilización de los recursos necesarios para el cumplimiento de las metas se obtuvieron los siguientes resultados:

Tabla 12. Grado de eficiencia en la utilización de los recursos

\begin{tabular}{l|crrr}
\multicolumn{1}{c|}{ Nombre del indicador } & Planificado & Ejecutado & $\begin{array}{r}\text { Cálculo } \\
\text { Ejecutado/ } \\
\text { Planificado }\end{array}$ & Brecha \\
\hline $\begin{array}{l}\text { Cantidad de dinero incrementado por la } \\
\text { disminución de las cuentas incobrables en el año } \\
\text { 2018. }\end{array}$ & 4600.00 & 4600.00 & $100.00 \%$ & $0.00 \%$ \\
\hline $\begin{array}{l}\text { Cantidad de dólares invertidos para alcanzar un } \\
\text { mayor nivel de satisfacción de los clientes. }\end{array}$ & 3000 & 2499.9 & $83.33 \%$ & $16.67 \%$ \\
\hline $\begin{array}{l}\text { Cantidad de dinero invertido para incrementar el } \\
\text { volumen de ventas en al año 2018 }\end{array}$ & 2800 & 2240 & $80.00 \%$ & $20.00 \%$ \\
\hline $\begin{array}{l}\text { Cantidad de dinero invertido en la capacitación del } \\
\text { personal de la empresa en el año 2018 }\end{array}$ & 3500 & 3333.5 & $95.24 \%$ & $4.76 \%$ \\
\hline Grado de eficiencia & & & $\mathbf{8 9 . 6 4 \%}$ & $\mathbf{1 0 . 3 6 \%}$ \\
\hline
\end{tabular}

Según lo demuestra la tabla 12, la empresa alcanzo un nivel de eficiencia del $89.64 \%$ en la utilización de sus recursos disponibles.

Y con relación al nivel de satisfacción por parte de los clientes, de los 96 usuarios que fueron encuestados $80(83.33 \%)$ están satisfechos por los bienes y servicios que ofrece Multimotos, según se evidencia en la tabla 13.

Tabla 13. Grado de satisfacción de los clientes de Multimotos S.A.

\begin{tabular}{l|rrrr}
\multicolumn{1}{c|}{ Nombre del indicador } & Planificado & Ejecutado & \multicolumn{1}{c}{ Cálculo } & \multirow{2}{*}{ Brecha } \\
& & & $\begin{array}{c}\text { Ejecutado/ } \\
\text { Planificado }\end{array}$ & \\
\hline Número de clientes satisfechos & & 86 & $83.33 \%$ & $16.67 \%$ \\
\hline Grado de satisfacción & 96 & 80 & $\mathbf{8 3 . 3 3 \%}$ & $\mathbf{1 6 . 6 7 \%}$ \\
\hline
\end{tabular}




\section{Conclusiones.}

La Auditoría de Gestión permitió examinar el grado y forma de cumplimiento de los objetivos de la empresa, así como el funcionamiento adecuado del sistema de control interno en apoyo al logro de la eficiencia y eficacia de las operaciones. Su ejecución requirió la identificación de todas las actividades, y controles de la empresa, para organizar aquellos que son esenciales para la gerencia y el uso adecuado de los recursos.

Se consideraron componentes importantes que sirven de base para el cumplimiento de sus objetivos empresariales, y que, a través del informe de auditoría, los directivos dispongan de una herramienta, que les permita tomar las acciones correctivas.

Para la evaluación del sistema de control interno se utilizó un cuestionario basado en el informe COSO, obteniendo un nivel de confianza alto y consecuentemente un nivel de riesgo bajo, aunque su nivel de confianza es aceptable (82\%) la gerencia debe supervisar y monitorear periódicamente el sistema de control interno, para asegurar su funcionamiento efectivo.

Se evaluó la eficacia y eficiencia en la ejecución de las metas programadas por la empresa para el año 2018, y cuyos resultados demostraron que la empresa, no cumple con la ejecución de las metas establecidas y no presenta las respectivas reprogramaciones, con la finalidad de contar con una correcta ejecución a lo planificado. Adicionalmente, no cumple con la ejecución y monto presupuestado.

\section{Recomendaciones.}

Se recomienda aplicar la auditoría de gestión como herramienta de control completa de la gestión de las instituciones tanto públicas como privadas; y que a través del informe de auditoría genere una opinión sobre la calidad, eficiencia, eficacia y economía de las operaciones y pueda prevenir y detectar inconformidades, así como prevenir y mitigar la posibilidad de que se comentan errores en la empresa intencionales o no.

Es importante que la gerencia disponga de una planificación estratégica u operativa para cada período, en el cuál se concreten, objetivos, indicadores, metas, programas, proyectos y actividades, vinculadas con el presupuesto y en función de su naturaleza y disponibilidad real de fondos, los mismos que deben ser difundidos entre todos los niveles de la empresa.

Evaluar al final de cada período, los resultados logrados, mediante un análisis situacional y del entorno, identificando los posibles hechos que implicaron desvíos a su programación. Se recomienda implementar dichas actividades de control, porque las mismas contribuyen al uso racional y efectivo de los recursos y facilitan alcanzar los objetivos empresariales. 


\section{Referencias bibliográficas.}

Alonso Ferreras, V. (2010). Factores críticos de éxito y evaluación de la competitividad de destinos turísticos. Estudios y Perspectivas en Turismo , 201-220.

Araya Navarro, J. (21 de mayo de 2019). Los hallazgos de auditoría interna en el sector público. Recuperado el 31 de Octubre de 2017, de http://www.iaicr.com/boletin/boletin07/hallazgos_auditoria_interna.pdf

Blanco Luna, Y. (2006). Auditoría Integral: Normas y Procedimientos. Bogotá: Ecoe Ediciones.

Cantos Ochoa, M. E. (2019). La auditoría integral como herramienta de validación de la gestión institucional. Telos. Revista de Estudios Interdisciplinarios en Ciencias Sociales, 422-448.

Contraloría General del Estado. (2001). Manual de Auditoría de Gestión. Quito: Edi- Abaco Cia. Ltda.

Contraloría General del Estado. (2003). Manual de Auditoría de Gestión. Quito: Corporación Edi-Abaco Cía. Ltda.

Contraloría General del Estado. (2009). Normas de Control Interno de la Contraloría General del Estado, Acuerdo No.39 CG, de 14 de diciembre. Ecuador.

De Salas Nestares, C., Arriaga Álvarez, E., \& Pla Velarde, E. (2006). Guía para auditorias del sistema de gestión de prevesión de riesgos laborales . Madrid: Ediciones Díaz de Santos.

Dextre, J., \& Del Pozo, R. (2012). Control de gestión o gestión de control. Contabilidad y Negocios, 69-80.

Franklin, E. (2007). Auditoría Administrativa: Gestión estratégica del cambio. México: Pearson Educación.

León Cornejo, M. (2012). Auditoría Financiera I: El proceso de auditoría financiera. Loja: Ediloja.

León Cornejo, M. (2014). Auditoría de Gestión 5. Loja: Ediloja.

Maldonado, M. (2006). Auditoría de Gestión. Quito: Abya Yala.

Navarro, Franlin y Ramos, Liliana (2016). El control interno en los procesos de produccion de la industria litografica en Barranquilla. Revista Equidad y Desarrollo, 245-267.

Normas Internacionales de Auditoría. (2002). Normas internacionales. México: NIA. 
Olalla Velásquez, E. (2014). Auditoria de gestion IV. Loja: Ediloja.

Pérez , J., \& Veiga, C. (2013). Control de la gestión empresarial. Madrid: Esic Editorial.

Rincón, R. (1998). Los indicadores de gestión organizacional: Una guía para su definción . Universidad Eafit, 44-59.

Romero Romero, E. (2013). Presupuesto público y contabilidad gubernamental . Bogotá: Ecoe Ediciones.

Subía Guerra, J. C. (2013). Auditoría de Gestión III. Loja: Ediloja.

Velásquez, M. (2013). Auditoría de Gestión I. Loja: Ediloja.

Velásquez, M. (2012). Auditoría Financiera II. Loja: Ediloja.

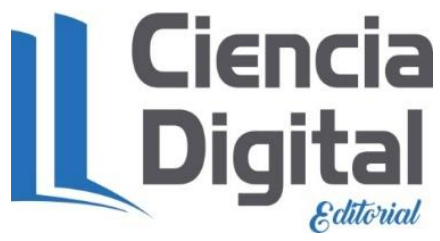




\section{PARA CITAR EL ARTÍCULO INDEXADO.}

Castillo Morocho, J., Erazo Álvarez, J., Narváez Zurita, C., \& Torres Palacios, M. (2019). Auditoría de gestión y su incidencia en la eficiencia y eficacia de las operaciones de una empresa comercial. Visionario Digital, 3(2.1.), 159-188.

https://doi.org/10.33262/visionariodigital.v3i2.1.551

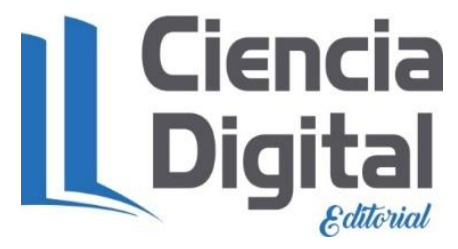

El artículo que se publica es de exclusiva responsabilidad de los autores y no necesariamente reflejan el pensamiento de la Revista Ciencia Digital.

El artículo queda en propiedad de la revista y, por tanto, su publicación parcial y/o total en otro medio tiene que ser autorizado por el director de la Revista Ciencia Digital.
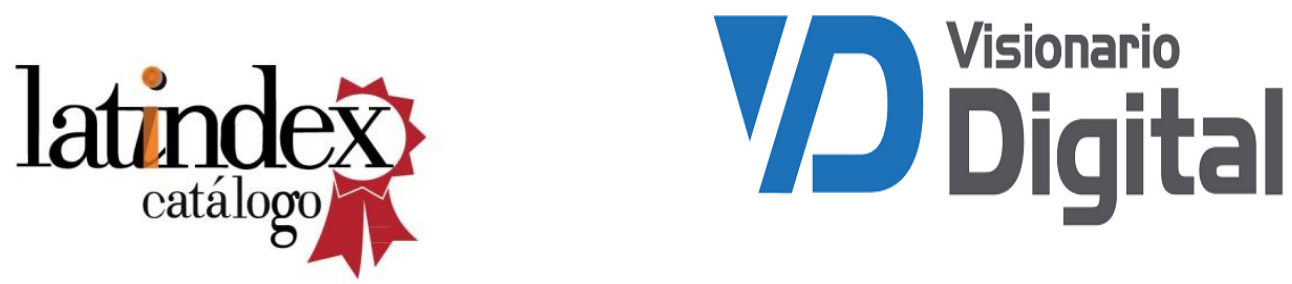